\title{
Small Colony Variants and Triclosan Resistance in Five International Clones of Methicillin Resistant Staphylococcus aureus
}

\author{
Al-Doori Z. ${ }^{1}$, Donald Morrison² \& J. Philpott-Howard ${ }^{3}$ \\ ${ }^{1}$ Clinical Scientist, Saltire Centre, Glasgow Caledonian University, Glasgow, Scotland, UK \\ ${ }^{2}$ Microbiology Lecturer, School of Applied Sciences, Edinburgh Napier University, Sighthill Campus, Sighthill \\ Court, Edinburgh EH11 4BN,Scotland, UK \\ ${ }^{3}$ Department of Medical Microbiology, King's College London School of Medicine (Denmark Hill Campus), \\ Bessemer Road, London SE5 9PJ, UK \\ Correspondence: Al-Doori Z., Clinical Scientist, Saltire Centre, Glasgow Caledonian University, Glasgow, \\ Scotland, UK. Tel: 44-0-786-171-2008. E-mail: zenatulab@gmail.com
}

Received: May 16, 2017

doi:10.5539/jmbr.v7n1p112
Accepted: June 23, 2017

Online Published: July 19, 2017

URL: https://doi.org/10.5539/jmbr.v7n1p112

\begin{abstract}
Triclosan (2.4.4' trichloro-2'-hydroxydiphenyl ether) is a broad-spectrum biocide which is also used to decolonise patients with methicillin resistant Staphylococcus aureus (MRSA). Microbial resistance to biocides has recently been reported, so it is important that new products should be tested for resistance that may arise from continued exposure to such agents. In a previous study 232 strains of MRSA isolated during 1997-2000 in 30 Scottish hospitals were tested for triclosan susceptibility; overall the minimum inhibitory concentrations (MIC) of triclosan for these strains ranged from $\leq 0.015$ to $4 \mathrm{mg} / \mathrm{L}$. In the present study, resistance to triclosan was examined in five major international MRSA clones [Clonal Complex (CC22, CC30, CC45, CC8 and CC5)] by growing them in brain heart infusion broth in the presence of increasing concentrations of triclosan $(0.03 \mathrm{mg} / \mathrm{L}, 0.06 \mathrm{mg} / \mathrm{L}, 0.125$ $\mathrm{mg} / \mathrm{L}, 0.25 \mathrm{mg} / \mathrm{L}$, and $0.5 \mathrm{mg} / \mathrm{L}$ ) for up to 67 days. Different MRSA clones showed different degrees of triclosan tolerance. CC22 (EMRSA-15), CC30 (EMRSA-16) and CC5 triclosan-tolerant derivatives showed a significant increase in triclosan MIC when compared to their parents, principally through the appearance of pinpoint-size small colony variants (SCV), as well as colonies of normal or small size. These MRSA SCVs emerged in different clones and at different times of exposure to triclosan. The triclosan MICs of mutants of all colony sizes rose to 4 $\mathrm{mg} / \mathrm{L}$ in all clones except MRSA111-29 (CC45) which had an MIC 4-8 mg/L. Triclosan-resistant MRSA strains were also able to grow in the presence of higher triclosan concentrations: $1.25 \mathrm{mg} / \mathrm{L}$ (CC22), $10 \mathrm{mg} / \mathrm{L}$ (CC30), 25 $\mathrm{mg} / \mathrm{L}$ (CC45), $5 \mathrm{mg} / \mathrm{L}$ (CC8) and $25 \mathrm{mg} / \mathrm{L}$ (CC5). In addition, six triclosan resistant derivatives from each MRSA clone, together with their parental clone, were examined by antibiogram, polymerase chain reaction (PCR) ribotyping and detailed susceptibility to triclosan in terms of MIC and kill kinetics. Susceptibility to the aminoglycosides kanamycin, neomycin and tobramycin was decreased in four clones, and tetracycline susceptibility increased in one clone. PCR ribotyping confirmed clonally similar to the mutants. Kill kinetics of both parents and their triclosan resistant mutants showed 5-Logs reduction at $0.5 \mathrm{~min}$ and $5 \mathrm{~min}$ respectively in all five clones. In conclusion, repeated exposure of MRSA to triclosan may result in resistance to this biocide, and to clinically-relevant antimicrobials.
\end{abstract}

Keywords: Triclosan, Methicillin Resistant Staphylococcus aureus, MRSA clones, Resistance, Small-colony variants

\section{Introduction}

Triclosan (2, 4, 4'-trichloro-2'-hydroxyphenyl ether) is a widely used antimicrobial agent that is found in a variety of consumer goods and in antiseptic products that are designed for use in the clinical setting (Brading et al., 2004; Yazdankah et al., 2006). Triclosan has been recommended as a topical agent for the decontamination of patients colonised with methicillin resistant Staphylococcus aureus (MRSA) in hospitals and the community, and is now widely used to control in-hospital MRSA outbreaks. It is important that such products should be tested for any microbial resistance that may arise from repeated and continued exposure over long periods of time. Not only in hospital and community, Couto et al. (2013) evaluated triclosan along with other biocides and antimicrobial susceptibility of methicillin-resistant staphylococcal isolates from horses. More recently, Forbes et al. (2015) 
investigated triclosan-induced generation of SCVs in six $S$. aureus strains, including methicillin-resistant $S$. aureus (MRSA).

Two hundred and thirty-two strains of MRSA isolated during 1997-2000 in 30 Scottish hospitals have previously been tested for triclosan susceptibility (Al-Doori et al., 2003). Overall the range of minimum inhibitory concentrations for triclosan against these strains was $\leq 0.015-4 \mathrm{mg} / \mathrm{L}$. The breakpoint of triclosan for staphylococci is uncertain.

Triclosan has a target-based mechanism, inhibiting the action of one of the enzymes of bacterial fatty acid biosynthesis, enoyl-acyl carrier protein reductase, the product of the fabI gene (McMurry et al., 1998). Brenwald and Fraise (2003) suggested that resistance is also caused by genes other than fabI. This finding has led to recent concern that microbes may become resistant to triclosan through both target-based and efflux-based mechanisms. In addition, small colony variants (SCVs), which are seen on agar culture of a range of bacteria, have been confirmed as a novel mechanism for triclosan resistance among certain isolates of MRSA (Seaman et al., 2007).

In this study we examined triclosan resistance in five international clonal complexes of MRSA, after exposing them to increasing concentrations of triclosan. This was followed by the characterization of the emergent triclosan resistant mutants, including SCVs, of the MRSA clones.

\section{Materials and Methods}

\subsection{Isolates}

Five strains of MRSA were obtained from the Scottish MRSA Reference Laboratory. Each strain represented one of the five clonal complexes of MRSA (Enright et al., 2002):
1) 00.9521. M (CC22).
2) $97.1948 . \mathrm{S}$ (CC5).
3) $00.9523 . \mathrm{R}(\mathrm{CC} 30)$.
4) $99.3759 . \mathrm{V}(\mathrm{CC} 8)$
5) 03.8996. T (CC45).

These strains were used as parents for the selection of triclosan resistant mutants in vitro.

\subsection{Selection of triclosan resistant mutants of MRSA.}

Triclosan (Irgasan DP300, Ciba Speciality Chemical Ltd. (Manchester, UK)) stock was prepared in ethanol (Li et al., 2002). Brain heart infusion (BHI) broth cultures were freshly prepared from powder (Oxoid, UK) with triclosan at final concentrations of: $0 \mathrm{mg} / \mathrm{L}$ (control), $0.03 \mathrm{mg} / \mathrm{L}, 0.06 \mathrm{mg} / \mathrm{L}, 0.125 \mathrm{mg} / \mathrm{L}, 0.25 \mathrm{mg} / \mathrm{L}$, and $0.5 \mathrm{mg} / \mathrm{L}$. Ten mls of broth were each inoculated with a single overnight blood agar colony from a pure culture of each MRSA clone. Each triclosan-BHI broth culture was incubated for 48 hours, which was extended to six days at $37^{\circ} \mathrm{C}$ for the slower-growing strains. Triclosan-BHI cultures of the five clones of MRSA were then streaked out onto blood agar (BA) plates to obtain single colonies and to check for purity of the cultures. The BA plates were incubated at $37^{\circ} \mathrm{C}$ overnight. When purified on BA plates all MRSA clones showed growth of small colony variants (SCV) at different times of exposure to triclosan; however some of them showed a mixed size of colonies at earlier stages of exposure to triclosan: purified colonies were of standard size, or of a smaller reduced size, or pin-head size (the small colony variants).

A sample of $(100 \mu \mathrm{L})$ of the original BHI-triclosan culture was then transferred to a fresh BHI broth $(9.9 \mathrm{~mL})$ that contained the next higher final concentration of triclosan, as described by Gradel et al (2005). The purity of triclosan-grown cultures was again tested by subculture onto BA plates. The emerging triclosan-resistant SCV cultures were frozen at minus $20^{\circ} \mathrm{C}$ on plastic beads for further characterization tests.

\subsection{Characterisation of triclosan-resistant mutants}

The following tests were carried out for triclosan resistant mutants using original parents' strains as controls:

1). Determination of MIC to triclosan of mutants and parents.

The MIC of triclosan for the resistant mutants and their parents were tested using a range of concentrations in BHI from $\leq 0.015-32 \mathrm{mg} / \mathrm{L}$, using an agar dilution method based on CLSI M7-A4 (NCCLS, 1997). Control strains were Staphylococcus hominis NCTC11320, Enterococcus faecalis NCTC12201 and Staphylococcus aureus ATCC29213. 


\section{2). Stability of triclosan resistant mutants:}

The stability of triclosan resistance among broth-grown mutants was tested by continuous sub-culturing of the mutants taken from BA plates. This was determined by inoculating these isolates into triclosan-free BHI broth for fifteen (15) cycles (a cycle means inoculating a colony into triclosan-free BHI broth followed by overnight incubation; then a $0.1 \mathrm{ml}$ sample of the overnight culture was added to $9.9 \mathrm{ml} \mathrm{BHI} \mathrm{broth,} \mathrm{and} \mathrm{incubated} \mathrm{overnight.}$ This was repeated fifteen times, including weekends). Six mutant colonies from each MRSA clone were chosen as follows: CC22 (resistant to $0.6 \mathrm{mg} / \mathrm{L}$ triclosan); CC5 (resistant to $25 \mathrm{mg} / \mathrm{L}$ ); CC30 (resistant to $10 \mathrm{mg} / \mathrm{L}$ ); CC8 (resistant to $2.5 \mathrm{mg} / \mathrm{L}$ ); and CC45 (resistant to $1.25 \mathrm{mg} / \mathrm{L}$ ). The MIC of triclosan was determined for the parents (as a control) and for the triclosan resistant mutants at the $5^{\text {th }}$ cycle, $10^{\text {th }}$ cycle and $15^{\text {th }}$ cycle respectively as described above. Finally, triclosan resistant mutants at the end of these cycles were tested for their resistance by growing them in $10 \mathrm{mls}$ of BHI with the following final concentrations of triclosan: $0.3 \mathrm{mg} / \mathrm{L}, 0.6 \mathrm{mg} / \mathrm{L}, 1.25 \mathrm{mg} / \mathrm{L}, 2.5$ $\mathrm{mg} / \mathrm{L}, 5 \mathrm{mg} / \mathrm{L}$, and $10 \mathrm{mg} / \mathrm{L}$.

3). Antibiotic resistance of triclosan resistant mutants:

The original triclosan-resistant SCV mutants and their parents were tested for their sensitivity to antibiotics by Stokes' disk diffusion method on nutrient agar (Oxoid, Basingstoke, UK) with S.aureus Oxford strain as control (Report of the working party on antibiotic sensitivity testing of the British Society of Antimicrobial Chemotherapy (BSAC), 1991).

4). Bactericidal assay of triclosan resistant mutants using 'Aquasept':

Kill kinetics for 'Aquasept' (Seton Healthcare Group plc; 100\% 'Aquasept' contains 2\% W/V triclosan) based on the European Standard EN1040 using neutralizer ZD30805 (formulated in the laboratory) for 5 min Neutralization. Triclosan resistant mutants and their parents were tested for their viability at the following contact times with Aquasept: $0 \mathrm{~min} ., 0.5 \mathrm{~min} ., 1 \mathrm{~min} ., 5 \mathrm{~min} ., 15 \mathrm{~min} ., 30 \mathrm{~min}$. and $1 \mathrm{hr}$. at room temperature. CC22 (after 50 days exposure to triclosan), CC30 (56 days), CC5 (54 days), CC8 (42 days) and CC45 (44 days) were tested. A 5-Log reduction was determined as described by Suller and Russell (1999).

\section{5). Characterization of the triclosan resistant small colony variants:}

16S-23S rRNA Spacer DNA polymorphism analysis or PCR-Ribotyping of triclosan resistant MRSA mutants:

This was carried out to compare small colony variants with parents for their clonality; it was carried out following a modification of Kumari et al., 1997. Each MRSA clone has a characteristic PCR-ribotyping profile. Bacterial cells were lysed for 10 minutes at $50 \mathrm{C}^{\circ}$ with 200U Achromopeptidase (Sigma A-3547) and NET buffer (10mM Tris, $1 \mathrm{mM}$ EDTA, $10 \mathrm{mM} \mathrm{NaCl}$ ). Two microliters of lysed bacterial cells was added to $12.5 \mathrm{uL}$ of Reddy Load PCR mix $(0.2 \mathrm{mM}$ of each dNTP, $3 \mathrm{mM} \mathrm{MgCl} 2,0.625 \mathrm{U}$ of Taq polymerase and Taq buffer [Abgene, Epsom.UK] containing $1 \mathrm{uM}$ of primers G1 [GAA/GTC/GTA/ACA/AGG] and N1 [CAA/GGC/ATC/CAC/CGT]). The primers have been published by Jensen et al 1993. The final volume is completed to $25 \mathrm{uL}$ using tissue-culture grade water (Sigma). PCR cycling conditions were as follows: 34 cycles at $95^{\circ} \mathrm{C}, 55^{\circ} \mathrm{C}$ and $72^{\circ} \mathrm{C}$ for $1 \mathrm{~min}$ each, followed by $7 \mathrm{~min}$ of final cycle of $72^{\circ} \mathrm{C}$. Biogene Phorecus agarose horizontal gel was prepared at $1.5 \%$ and loaded with $6 \mathrm{uL}$ of PCR products. Electrophoresis was performed in $0.5 \mathrm{x}$ Tris/Borate/EDTA buffer at $100 \mathrm{~V}$ for $9 \mathrm{hrs}$. The gels were stained with ethidium bromide $(1 \mu \mathrm{g} / \mathrm{mL})$ followed by examination and photography under UV using a computerized UVP system. Controls were NCTC10442, EMRSA-15 (UN25) and EMRSA-16 (UN35).

\section{Results}

\subsection{Isolation of triclosan resistant mutants}

Triclosan resistant MRSA (tables1A \& 1B) were observed to grow at the following higher concentrations of triclosan: CC22 (1.25 mg/L), CC30 (10 mg/L), CC45 (25 mg/L), CC8 (5 mg/L) and CC5 (25 mg/L). MRSA SCVs emerged at different times of exposure to triclosan; they were noticed on BA plates and produced much less turbidity in BHI triclosan broth cultures. Their emergence was not restricted to a distinct clonal lineage (Table 1B). Early emergence of triclosan resistant SCVs was noticed in CC22 and CC5 followed by CC30 whereas CC45 and CC8 showed a delay. The resistant colonies from the five clones were variably of normal size, small size and the pin-head size SCVs. 
Table1A. Exposure of five international clones of MRSA to triclosan

\begin{tabular}{lllll}
\hline MRSA Clone & $\begin{array}{l}\text { Initial MIC } \\
\mathrm{mg} / \mathrm{L}^{*}\end{array}$ & $\begin{array}{l}\text { Duration of Exposure } \\
\text { days }\end{array}$ & $\begin{array}{l}\text { Growth at Concentration } \\
\mathrm{mg} / \mathrm{L}\end{array}$ & $\begin{array}{l}\text { MIC last Passage } \\
\mathrm{mg} / \mathrm{L}\end{array}$ \\
\hline $\mathrm{CC} 22$ & 0.015 & 51 & 1.25 & 4 \\
$\mathrm{CC} 30$ & 0.015 & 61 & 10 & $2-4$ \\
$\mathrm{CC} 45$ & 1 & 67 & 25 & 4 \\
$\mathrm{CC} 8$ & 1 & 60 & 5 & 4 \\
$\mathrm{CC} 5$ & 0.03 & 60 & 25 & 4 \\
\hline
\end{tabular}

Legend Table1A. Initial triclosan MIC (mg/L), the duration of exposure (days) of MRSA clones to triclosan, the concentration of triclosan at which MRSA were able to grow $(\mathrm{mg} / \mathrm{L})$ and the final MIC triclosan of MRSA at the last passage.

* Al-Doori Z et al. (2003)

Table 1B. Development of triclosan resistant mutants in MRSA clones

\begin{tabular}{llllll}
\hline MRSA Clone & $\begin{array}{l}\text { Mutants Cycle } \\
\text { (number) }\end{array}$ & $\begin{array}{l}\text { Triclosan }^{\mathrm{R}} \\
\text { mutants }\end{array}$ & $\begin{array}{l}\text { Exposure } \\
\text { Days }\end{array}$ & $\begin{array}{l}\text { Growth at Triclosan } \\
\mathrm{mg} / \mathrm{L}\end{array}$ & $\begin{array}{l}\text { MIC of Triclosan } \\
\mathrm{mg} / \mathrm{L}\end{array}$ \\
\hline CC22 & 5 & SCV & 12 & 0.6 & 4 \\
CC30 & 7 & Normal & 35 & 1.25 & 2 \\
CC30 & 8 & SCV & 39 & 1.25 & 4 \\
CC30 & 11 & Reduced size & 45 & 1.25 & 2 \\
CC5 & 5 & Reduced size & 20 & 2.5 & 4 \\
CC5 & 5 & Normal & 20 & 2.5 & 2 \\
CC5 & 7 & SCV & 30 & 2.5 & 2 \\
CC8 & 9 & Normal & 33 & 2.5 & 4 \\
CC8 & 14 & Reduced size & 46 & 1.25 & 2 \\
CC8 & 28 & SCV & 60 & 2.5 & 2 \\
CC45 & 10 & Normal & 40 & 2.5 & 8 \\
CC45 & 12 & Reduced size & 44 & 1.25 & 8 \\
CC45 & 15 & SCV & 48 & 1.25 & 4 \\
\hline
\end{tabular}

Legend Table 1B. Development of triclosan resistant mutants in MRSA clones showing the cycle at which mutants were derived, the type of mutants as far as size of colony is concerned, when did they appear and at which tricolsan concentration. The triclosan MIC of these mutants is shown in the right hand column (see Materials \& Methods).

Abbreviation: SCV, small colony variants. $R$., is resistant

\subsection{Kill Kinetics of triclosan resistant mutants}

The kill kinetics of parent(s) clones and their triclosan resistant mutants showed 5-Log reduction at 0.5 min and 5 min respectively in all five clones. There was a significant increase of time for 5-Log reduction in the case of triclosan resistant mutants.

\subsection{Clonality testing of triclosan resistant mutants}

16S-23S rRNA spacer length polymorphism analysis or PCR-ribotyping showed similar clonality of the triclosan resistant mutants to their parents on gel electrophoresis (Figure 3).

\subsection{MIC tests for triclosan resistant mutants}

The MIC of triclosan for each of the mutants rose to $4 \mathrm{mg} / \mathrm{L}$ in all clones except MRSA111-29 (CC45) which had a range of MIC 4-8 $\mathrm{mg} / \mathrm{L}$.

\subsection{Stability tests of triclosan resistant mutants}

The test for the stability of triclosan resistant mutants when subcultured in triclosan-free broth showed that in all clones the triclosan MIC remained at $4 \mathrm{mg} / \mathrm{L}$. Triclosan-R CC22 (42 -51 days) mutants were resistant to $4 \mathrm{mg} / \mathrm{L}$; triclosan-R CC30 (32-61 days) were resistant to 2-4 mg/L; triclosan-R CC45 was less susceptible to triclosan as resistance appeared at a lower concentration of $1 \mathrm{mg} / \mathrm{L}$ and in $16-41$ days they were resistant to $8 \mathrm{mg} / \mathrm{L}$; later (68 days) they were resistant to $4 \mathrm{mg} / \mathrm{L}$ of triclosan). Triclosan-resistant CC8 showed resistance to $4 \mathrm{mg} / \mathrm{L}$ (even after 
60 days exposure). Triclosan-resistant strain CC5 showed resistance to $2 \mathrm{mg} / \mathrm{L}$ (20 days) and to $4 \mathrm{mg} / \mathrm{L}$ (between 55-60 days). Table 2 shows triclosan resistant mutants and their stability. Furthermore, it illustrates bactericidal activity of triclosan for the parental clones and the derived triclosan resistant mutants of all five MRSA clones at the latest time of triclosan exposure of Day 50, Day 56 for EMRSA CC22 and CC30 respectively. All of CC5 at Day 54, CC8 at Day 42 and CC45 at Day 44 showed five logs reduction at 5 minutes.

Table 2. Analysis of triclosan resistant mutants and their stability

\begin{tabular}{|c|c|c|c|c|c|c|c|}
\hline Clonal Complex & Exposure & $\begin{array}{l}\text { Triclosan } \\
\text { MIC }\end{array}$ & $\begin{array}{l}5 \operatorname{Logs} \\
\text { Reduction }\end{array}$ & $\begin{array}{l}\mathrm{Cfu} / \mathrm{ml} \\
0 \\
\text { minute }\end{array}$ & $\begin{array}{l}\mathrm{Cfu} / \mathrm{ml} \\
0.5 \\
\text { minute } \\
\end{array}$ & $\begin{array}{l}\mathrm{Cfu} / \mathrm{ml} \\
1.0 \\
\text { minute } \\
\end{array}$ & $\begin{array}{l}\mathrm{Cfu} / \mathrm{ml} \\
5.0 \\
\text { minutes }\end{array}$ \\
\hline CC22-Parent & Day 0 & 0.015 & $0.5 \mathrm{~min}$ & $1.8 \times 10^{8}$ & No growth & No growth & No growth \\
\hline CC22:Trc-r & Day 50 & 4 & $5 \mathrm{~min}$ & $1.9 \times 10^{9}$ & $1.4 \times 10^{6}$ & $8 \times 10^{4}$ & No growth \\
\hline CC22:Trc-St & 15 Passages & 4 & - & - & - & - & - \\
\hline CC30-Parent & Day 0 & 0.015 & $0.5 \mathrm{~min}$ & $8.8 \times 10^{7}$ & No growth & No growth & No growth \\
\hline CC30:Trc-r & Day 56 & 4 & $5 \mathrm{~min}$ & $4.8 \times 10^{8}$ & $8 \times 10^{2}$ & $3.2 \times 10^{4}$ & No growth \\
\hline CC30:Trc-St & 15 Passages & 4 & - & - & - & - & - \\
\hline CC5-Parent & Day 0 & 0.015 & $0.5 \mathrm{~min}$ & $5.2 \times 10^{7}$ & No growth & No growth & No growth \\
\hline CC5:Trc-r & Day 54 & 4 & $5 \mathrm{~min}$ & $1.3 \times 10^{9}$ & $2.4 \times 10^{5}$ & $4.4 \times 10^{4}$ & No growth \\
\hline CC5:Trc-St & 15 Passages & 4 & - & - & - & - & - \\
\hline CC8-Parent & Day 0 & 1 & $0.5 \mathrm{~min}$ & $5.2 \times 10^{7}$ & No growth & No growth & No growth \\
\hline CC8:Trc-r & Day 42 & 4 & $5 \mathrm{~min}$ & $1.4 \times 10^{9}$ & $5.2 \times 10^{5}$ & $6.8 \times 10^{4}$ & No growth \\
\hline $\mathrm{CC} 8:$ Trc-St & 15 Passages & 4 & - & - & - & - & - \\
\hline CC45-Parent & Day 0 & 1 & $0.5 \mathrm{~min}$ & $8.8 \times 10^{7}$ & No growth & No growth & No growth \\
\hline CC45:Trc-r & Day 44 & 8 & $5 \mathrm{~min}$. & $9.2 \times 10^{8}$ & $3.2 \times 10^{6}$ & $8.4 \times 10^{4}$ & No growth \\
\hline CC45:Trc-St & 15 Passages & 4 & - & - & - & - & - \\
\hline
\end{tabular}

Legend Table 2. Abbrev: Trc-r: triclosan resistant mutants. Trc-St: triclosan resistant variant after 15 serial sub-cultures in triclosan free Broth (Stability experiment). Exposure: isolates exposed to triclosan through serial sub-culture in increasing concentration. Triclosan MIC is in $\mathrm{mg} / \mathrm{L}$. 5Logs Reduction.: is reduction as to bactericidal assay of triclosan

\subsection{Emergence of Small Colony Variants}

SCVs appeared before 12 days of exposure for CC22 (Arrow Figure 1; Figure 2). The MIC of triclosan for the resistant mutants was $4 \mathrm{mg} / \mathrm{L}$; following serial passages in triclosan-free broth, the MIC of all five resistant isolates at the end of the fifteenth cycle remained at $4 \mathrm{mg} / \mathrm{L}$, indicating stability of the triclosan resistance mutation(s). SCVs which were triclosan resistant displayed similar PCR ribotyping pattern as that of their clonally similar parent, and similar triclosan MICs as the triclosan-resistant MRSA of the same clone even if not an SCV. Kill kinetics of the tolerant isolates (5-Log reduction after $5 \mathrm{~min}$ contact time) was slower than for the parents.

\subsection{Susceptibility to Antibiotics of Triclosan Resistant Mutants \& Morphological Appearances on Agar}

Triclosan tolerant MRSA including SCVs had altered susceptibility to a range of antibiotics (table 3) compared with parent strains e.g. CC22 became resistant to kanamycin and tobramycin, $\mathrm{CC} 30$ became resistant to neomycin, similar to CC5, whereas CC45 SCVs became more sensitive to tetracycline (table 3). Morphological observations on triclosan resistant mutants of some MRSA clones showed that MRSA-105 (CC5) growth was very tightly adherent to the surface of the blood agar plate. In contrast, triclosan resistant MRSA111-29 (CC45) showed hygroscopic colonies on blood agar plate. 


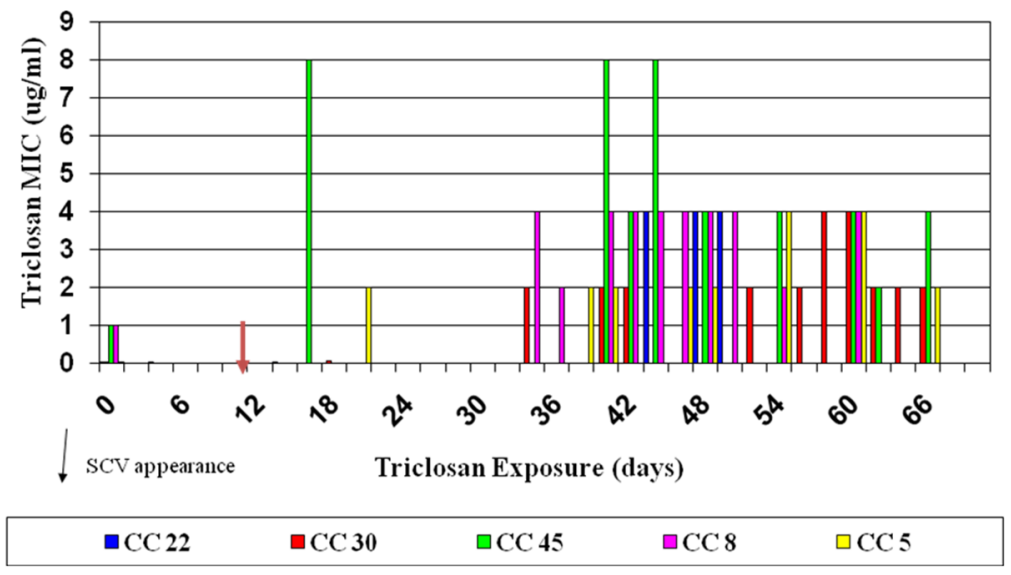

Figure 1. Emergence of triclosan resistance in five international clones of MRSA. Arrow refers to the first appearance of small colony variants (SCVs) for Clonal Complex CC22

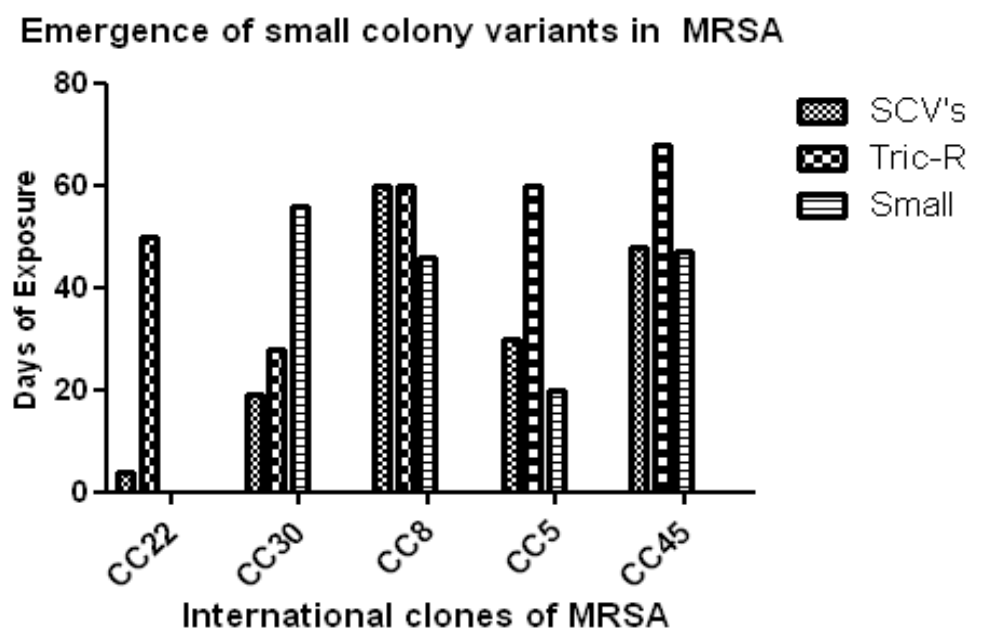

Figure 2. Emergence of triclosan resistant small-colony variants with respect to days of exposure of MRSA to triclosan in five international clones

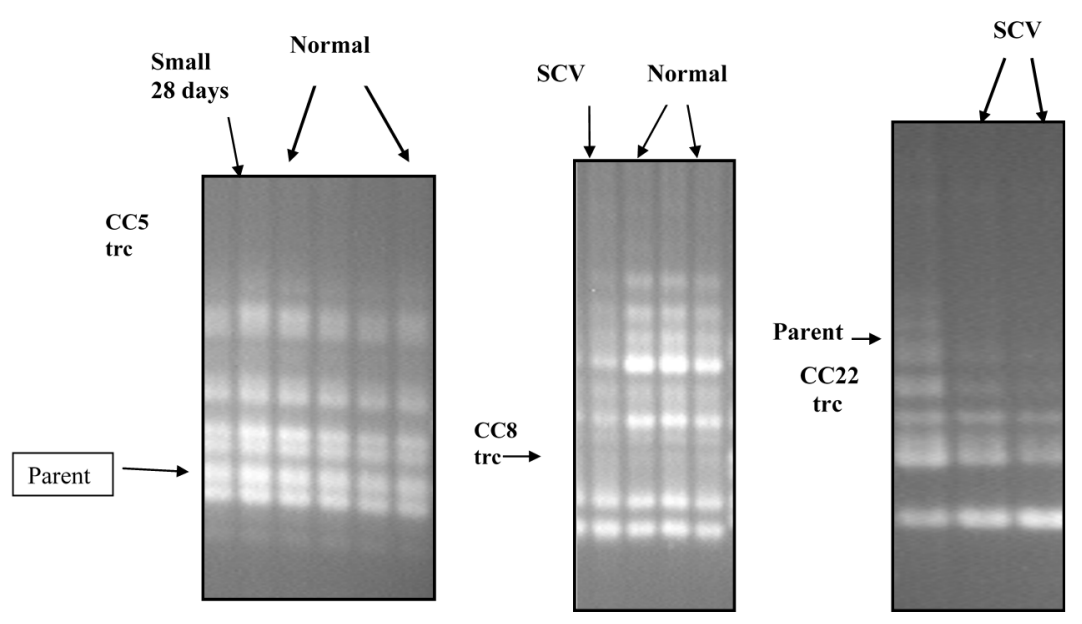

Figure 3. PCR Ribotyping results showing similarity in patterns between parents MRSA clones and triclosan resistant mutants of normal size, small size and small colony variants 
Table 3. Characterization of triclosan resistant MRSA mutants

\begin{tabular}{|c|c|c|c|c|c|c|c|c|}
\hline \multirow[t]{2}{*}{ MRSA Clone } & \multicolumn{5}{|c|}{ AB Susceptibility } & \multirow[t]{2}{*}{ PCR Ribo. } & \multirow[t]{2}{*}{ MIC Tric. } & \multirow[t]{2}{*}{ Colonies Morphology } \\
\hline & Kan & Tob & Neo & Tet & $\mathrm{Gm}$ & & & \\
\hline CC22-Parent & $\mathrm{S}$ & $\mathrm{S}$ & $\mathrm{S}$ & $\mathrm{S}$ & $\mathrm{S}$ & PR15 & 0.015 & Normal \\
\hline CC22-Trc-r & $\mathrm{S}$ & S & $\mathrm{S}$ & - & $\mathrm{S}$ & PR15 & 4 & Pinpoint Size \\
\hline $\mathrm{CC} 22-\mathrm{SCV}$ & $\mathrm{R}$ & $\mathrm{R}$ & S & - & S & PR15 & 4 & Pinpoint Size \\
\hline CC30-Parent & $\mathrm{R}$ & $\mathrm{R}$ & $\mathrm{S}$ & - & $\mathrm{S}$ & PR16 & 0.015 & Normal \\
\hline CC30-Trc-r & $\mathrm{R}$ & $\mathrm{R}$ & $\mathrm{R}$ & - & S & PR16 & 2 & Normal \\
\hline CC30-SCV & $\mathrm{R}$ & $\mathrm{R}$ & $\mathrm{R}$ & - & $\mathrm{S}$ & PR16 & 2 & Pinpoint Size \\
\hline CC5-Parent & I & $\mathrm{R}$ & S & - & S & PR105 & 0.03 & Normal \\
\hline CC5-Trc-r & $\mathrm{R}$ & $\mathrm{R}$ & $\mathrm{R}$ & - & $\mathrm{S}$ & PR105 & 4 & Adhere tightly to agar \\
\hline CC5-SCV & $\mathrm{R}$ & $\mathrm{R}$ & $\mathrm{R}$ & - & S & PR105 & 4 & Adhere tightly to agar \\
\hline CC8-Parent & $\mathrm{R}$ & $\mathrm{R}$ & I & $\mathrm{R}$ & $\mathrm{R}$ & PR109 & 1 & Normal \\
\hline CC8-Trc-r & $\mathrm{R}$ & $\mathrm{R}$ & $\mathrm{R}$ & $\mathrm{R}$ & $\mathrm{R}$ & PR109 & 4 & All normal, small \&SCV \\
\hline CC8-SCV & $\mathrm{R}$ & $\mathrm{R}$ & $\mathrm{R}$ & $\mathrm{R}$ & $\mathrm{R}$ & PR109 & 4 & Pinpoint Size \\
\hline CC45-Parent & $\mathrm{R}^{\mathrm{i}}$ & $\mathrm{R}$ & $\mathrm{R}^{\mathrm{i}}$ & $\mathrm{R}$ & S & PR111 & & Normal \\
\hline CC45-Trc-r & $\mathrm{R}$ & $\mathrm{R}$ & $\mathrm{R}$ & S & S & PR111 & $4-8$ & Hygroscopic. Small \\
\hline CC45-SCV & $\mathrm{R}$ & $\mathrm{R}$ & $\mathrm{R}$ & $\mathrm{S}$ & $\mathrm{S}$ & PR111 & $4-8$ & Pinpoint Size \\
\hline
\end{tabular}

Legend Table 3 The characterisation of triclosan resistant MRSA mutants showing their antibiotic susceptibility, PCR Ribotyping, MIC triclosan and the colony morphology. For antibiotics susceptibility the following disc concentrations were used: Kan (30) and $10 \mathrm{mg} / \mathrm{L}$ for each of the rest of antibiotics.

Abbrev: AB: antibiotics, S: Sensitive, R: Resistant, I: Intermediate.Kan: Kanamycin, Tob: Tobramycin, Neo: Neomycin,

Tet: Tetracycline, Gm: Gentamicin

\section{Discussion}

Triclosan is a widely used biocide that is considered to be an effective antimicrobial agent against different microorganisms. Since 2000, a number of studies have verified the occurrence of triclosan resistance amongst dermal, intestinal and environmental microorganisms including some of clinical relevance (Yazdankah et al., 2006). Staphylococcus aureus can produce small-colony variants (SCVs) that express different phenotypes. While their importance is uncertain, SCV propagation may be influenced by relative fitness, antimicrobial susceptibility, and the underlying mechanism (Forbes et al., 2015). Some workers were unable to demonstrate development of resistance following exposure of S.aureus to sub-minimum inhibitory concentrations of triclosan (Suller \& Russell, 2000) but low-level resistance had been reported previously in Escherichia coli and S. aureus including MRSA (Cookson et al., 1991); the resistance in these organisms is due to either fabI mutation leading to over-expression of reductase or over-expression of efflux pumps (Bayston et al., 2007). Triclosan is bacteriostatic at low concentration and bactericidal at higher concentration (Russell A.D., 2004A); in our experiments triclosan was not totally bactericidal following continuous exposure of MRSA clones, hence triclosan resistant mutants emerged. Triclosan is known to inhibit the enoyl acyl carrier protein reductase effectively (Pidugu et al., 2004). Selection for triclosan resistant mutants has been previously reported to result in the emergence of small colony variants (SCVs) of MRSA (Al-Doori et al., 2006; Seaman et al., 2007). Small colony variants show slow growth because cell wall synthesis requires large quantities of ATP; they show decreased pigment formation because carotenoid biosynthesis requires electron transport. Small colony variants also show resistance to aminoglycosides, as their uptake requires the large membrane potential generated by electron transport. Finally, their utilization of mannitol (sugar alcohol) is decreased when electron transport is not used.

Triclosan resistant SCVs did not show any alteration in their 16S-23S rRNA spacer length polymorphisms pattern from the parents; SCVs had similar MICs of triclosan compared to the non-SCV triclosan resistant mutants of the same clone, despite their obvious phenotypical changes. They emerged at earlier stages in clones CC22 and CC30; these are the most common epidemic clones in UK comprising $70 \%$ and $21 \%$ of MRSA isolates respectively. SCVs emerged earliest at the $10^{\text {th }}$ cycle of EMRSA-15 (CC22) before the $12^{\text {th }}$ day of exposure to triclosan, but much later in CC8 and CC45. This is different from triclosan resistant SCVs of Bayston et al. (2007); their SCVs emerged after just over two day's incubation (51hrs). The maintenance of the MIC among triclosan resistant mutants at $4 \mathrm{mg} / \mathrm{L}$ even after serial passage in triclosan-free broth reflects the stability of triclosan resistance 
among MRSA clones that were tested. This agrees with the results of Bayston et al. (2007) when resistant mutants were tested for their reversion to wild type and were found to be stable; the MIC of triclosan among SCVs in this study rose significantly. Continuous exposure of MRSA clones to triclosan resulted in decreased susceptibility to triclosan whereas others were unable to achieve that in S.aureus earlier (Suller \& Russell, 1999).

Concern has been expressed about the potential for agents such as triclosan to select for strains resistant to multiple clinically-relevant antibiotics (Poole, 2002). Antibiotic susceptibilities of triclosan resistant mutants including SCVs were carried out to examine this. We could not agree with the earlier conclusion of Russell (2000) that no relation could be found between antibiotic resistance and biocide (triclosan) resistance. A potential concern is that widespread usage of biocides is responsible for the selection and maintenance of antibiotic resistant bacteria (Russell, 2002A). Our results showed that there is a relationship between the change in profile of antibiotic susceptibility and acquired triclosan resistance. Levy (2002) pointed out that the prudent use of antibiotics and biocides will guard against the selection and propagation of drug-resistant mutants and preserve the efficacy of these valuable anti-infective agents. However, Bayston et al. (2007) reported that susceptibility to gentamicin is altered and SCVs became gentamicin sensitive. In our hands too, SCVs were gentamicin sensitive and did not develop resistance; MRSA CC8 as the parent clone was gentamicin resistant and did not become susceptible. Susceptibility of SCVs to three widely used antimicrobials (penicillin, gentamicin and triclosan) has been shown to reduce notably (Seaman et al., 2007). Small colony variants of Staphylococcus aureus, first described 100 years ago are more resistant to antibiotics (Proctor et al., 1998) than normal colonies; however, Forbes et al. (2015) found that triclosan susceptibility in all SCVs (which could be generated from 4/6 strains) was distinctly declined, while antibiotic susceptibility was considerably augmented in most of the cases. Clinical studies suggest a link between electron transport-defective strains and persistent infections, a defined hemB mutant with SCV phenotype provided strong additional evidence for these connections (Von Eiff $\mathrm{C}$ et al., 2000A). Therefore SCVs may account for persistance or antibiotic treatment failure. There are many reports and perspective studies supporting a pathogenic role for SCV in disease (Kipp, 2003; on Eiff et al., 2006). The publication by Kipp et al. (2003) in which SCVs of MRSA have been identified as causative organisms in a patient with a brain abscess was the first such report. To our knowledge, this is the first report of the emergence of SCVs due to exposure to biocides in the five international clonal complexes of MRSA; the evolutionary history of these clones was described earlier (Enright et al., 2002). Our results showed that triclosan resistant SCV are also resistant to antibiotics such as aminoglycosides and some showed resistance to trimethoprim-sulfamethoxazole and this confirms their characteristics described by Looney (2000). A defect in the electron transport system allows S.aureus SCVs to resist aminoglycosides and persist intracellularly (von Eiff C. et al., 2006). Spanu et al. (2005) reported that MRSA SCVs were misidentified by routine microbiological methods and were the cause of recurrent ventriculoperitoneal shunt-related meningitis. The clinical significance of emergence of triclosan resistance in the five MRSA clones is not clear but the emergence of SCVs is clinically significant; their role in the virulence and pathogenicity of bacteria has recently been investigated (Seaman et al., 2007). Patients treated with topical triclosan in hospital and staying for a long period, though not recommended, must be then tested for the presence of SCVs. Seaman et al. (2007) reported that the resistance in SCVs does not follow the classical mechanism of antimicrobial resistance such as chromosomal mutation, plasmid or transposing elements but is instead a direct consequence of the SCV phenotype. Biocides have multiple targets and increased MIC often does not correlate with decreased bactericidal activities of that compound (Seaman et al., 2007); in our experiment increased MIC triclosan was accompanied by reduced effectiveness of triclosan when comparing triclosan resistant mutant and SCVs with original parents of the five international clones of MRSA. Little is known about the uptake of triclosan into MRSA. Representatives of the five international clones of MRSA responded differently when exposed to increasing concentrations of triclosan as revealed by the duration of the emergence of SCV mutants and by MIC of triclosan resistant mutants when compared to their parent strains. Looking at the alteration of the antibiotics susceptibility test such that what we observed in CC45 resistance to neomycin and kanamycin; CC8 resistance to neomycin; CC5 resistance to neomycin, tobramycin, rifampicin and cefuroxime; $\mathrm{CC} 22$ resistance to kanamycin, tobramycin, rifampicin and trimethoprim and finally $\mathrm{CC} 30$ resistance to neomycin but sensitivity to chloramphenicol, we conclude that the widespread use of triclosan could lead to MRSA SCV appearance and the emergence of different patterns of antibiotic resistance which need to be tested in a clinical settings.

\section{Acknowledgment}

We would like to thank Ciba Speciality Chemical Ltd. (Manchester, UK) for the gift of Triclosan (Irgasan DP300) and for financial support. We are grateful to Prof.Curtis Gemmell for scientific supervision and support of the work. 


\section{Funding}

This work was funded by the Scottish MRSA Reference Laboratory and Ciba Speciality Chemical Ltd. (Manchester, UK).

\section{Conflict of Interest:}

Authors indicate that they have no conflict of interest.

\section{References}

Al-doori, Z., Morrison, D., Edwards, G., \& Gemmell, C. G. (2006). Investigation of tolerance to triclosan of five international Mrsa clones. Clinical Microbiology \& Infection, 12, 379.

Al-Doori, Z., Morrison, D., Edwards, G., \& Gemmell, C. (2003). Susceptibility of MRSA to triclosan. Journal of Antimicrobial Chemotherapy, 51(1), 185-186.

Bayston, R., Ashraf, W., \& Smith, T. (2007). Triclosan resistance in methicillin-resistant Staphylococcus aureus expressed as small colony variants: a novel mode of evasion of susceptibility to antiseptics. Journal of antimicrobial chemotherapy, 59(5), 848-853.

Brading, M. G., Cromwell, V. J., Green, A. K., DeBrabander, S., Beasley, T., \& Marsh, P. D. (2004). The role of Triclosan in dentifrice formulations, with particular reference to a new $0.3 \%$ Triclosan calcium carbonatebased system. International dental journal, 54(S5), 291-298.

Brenwald, N. P., \& Fraise, A. P. (2003). Triclosan resistance in methicillin-resistant Staphylococcus aureus (MRSA). Journal of Hospital Infection, 55(2), 141-144.

Cookson, B. D., Farrelly, H., Stapleton, P., Garvey, R. P. J., \& Price, M. R. (1991). Transferable resistance to triclosan in MRSA. The Lancet, 337(8756), 1548-1549.

Couto, N., Belas, A., Tilley, P., Couto, I., Gama, L. T., Kadlec, K., ... \& Pomba, C. (2013). Biocide and antimicrobial susceptibility of methicillin-resistant staphylococcal isolates from horses. Veterinary microbiology, 166(1), 299-303.

Enright, M. C., Robinson, D. A., Randle, G., Feil, E. J., Grundmann, H., \& Spratt, B. G. (2002). The evolutionary history of methicillin-resistant Staphylococcus aureus (MRSA). Proceedings of the National Academy of Sciences, 99(11), 7687-7692.

Forbes, S., Latimer, J., Bazaid, A., \& McBain, A. J. (2015). Altered competitive fitness, antimicrobial susceptibility, and cellular morphology in a triclosan-induced small-colony variant of Staphylococcus aureus. Antimicrobial agents and chemotherapy, 59(8), 4809-4816.

Gradel, K. O., Randall, L., Sayers, A. R., \& Davies, R. H. (2005). Possible associations between Salmonella persistence in poultry houses and resistance to commonly used disinfectants and a putative role of mar. Veterinary microbiology, 107(1), 127-138.

Jensen, M. A., Webster, J. A., \& Straus, N. (1993). Rapid identification of bacteria on the basis of polymerase chain reaction-amplified ribosomal DNA spacer polymorphisms. Applied and Environmental Microbiology, 59(4), 945-952.

Kipp, F., Ziebuhr, W., Becker, K., Krimmer, V., Höß, N., Peters, G., \& Von Eiff, C. (2003). Detection of Staphylococcus aureus by $16 \mathrm{~S}$ rRNA directed in situ hybridisation in a patient with a brain abscess caused by small colony variants. Journal of clinical pathology, 56(10), 746-746.

Kumari, D. N., Keer, V., Hawkey, P. M., Parnell, P., Joseph, N., Richardson, J. F., \& Cookson, B. (1997). Comparison and application of ribosome spacer DNA amplicon polymorphisms and pulsed-field gel electrophoresis for differentiation of methicillin-resistant Staphylococcus aureus strains. Journal of clinical microbiology, 35(4), 881-885.

Levy, S. B. (2002). Active efflux, a common mechanism for biocide and antibiotic resistance. Journal of applied microbiology, 92(s1), 65S-71S.

Li, J., Zhao, H. Y., Peng, G. K., Tian, P. Y., \& Li, C. Q. (2002). Determination and stability tests of triclosan in disinfectants. Se pu= Chinese journal of chromatography, 20(4), 372-374.

Looney, W. J. (2000). Small-colony variants of Staphylococcus aureus. British journal of biomedical science, 57(4), 317-322. 
McMurry, L. M., Oethinger, M., \& Levy, S. B. (1998). Triclosan targets lipid synthesis. Nature, 394(6693), 531-532.

National Committee for Clinical and laboratory standards Institute (1997). Methods for dilution antimicrobial Susceptibility tests for bacteria that grow aerobically fourth edition: Approved standard M7-A4. 1997. NCCLS, Wayne, PA, USA.

Pidugu, L. S., Kapoor, M., Surolia, N., Surolia, A., \& Suguna, K. (2004). Structural basis for the variation in triclosan affinity to enoyl reductases. Journal of molecular biology, 343(1), 147-155.

Poole, K. (2002). Mechanisms of bacterial biocide and antibiotic resistance. Journal of Applied Microbiology, $92(\mathrm{~s} 1), 55 \mathrm{~S}-64 \mathrm{~S}$.

Proctor, R. A., Kahl, B., von Eiff, C., Vaudaux, P. E., Lew, D. P., \& Peters, G. (1998). Staphylococcal small colony variants have novel mechanisms for antibiotic resistance. Clinical Infectious Diseases, 27(Supplement_1), S68-S74.

Phillips, P., Andrews, J. M., Bridson, E., Cooke, E. M., Holt, H. A., Spencer, R. C., ... \& King, M. (1991). A guide to sensitivity testing. Journal of Antimicrobial Chemotherapy, 27, 1-47.

Russell, A. D. (2000). Do biocides select for antibiotic resistance? J Pharm Pharmacol, 52, $227-233$.

Russell, A. D. (2004A). whither triclosan? J Antimicrob Chemother, 53(5), 693-695.

Seaman, P. F., Ochs, D., \& Day, M. J. (2006). Small-colony variants: a novel mechanism for triclosan resistance in methicillin-resistant Staphylococcus aureus. Journal of antimicrobial chemotherapy, 59(1), 43-50.

Spanu, T., Romano, L., D'inzeo, T., Masucci, L., Albanese, A., Papacci, F., ... \& Fadda, G. (2005). Recurrent ventriculoperitoneal shunt infection caused by small-colony variants of Staphylococcus aureus. Clinical Infectious Diseases, 41(5), e48-e52.

Suller, M. T. E., \& Russell, A. D. (1999). Antibiotic and biocide resistance in methicillin-resistant Staphylococcus aureus and vancomycin-resistant enterococcus. Journal of Hospital Infection, 43(4), 281-291.

Suller, M. T. E., \& Russell, A. D. (2000). Triclosan and antibiotic resistance in Staphylococcus aureus. Journal of Antimicrobial Chemotherapy, 46(1), 11-18.

Von Eiff, C., Proctor, R. A., \& Peters, G. (2000). Staphylococcus aureus small colony variants: formation and clinical impact. International journal of clinical practice. Supplement, (115), 44-49.

von Eiff, C., Peters, G., \& Becker, K. (2006). The small colony variant (SCV) concept - the role of staphylococcal SCVs in persistent infections. Injury, 37(2), S26-S33.

Yazdankhah, S. P., Scheie, A. A., Høiby, E. A., Lunestad, B. T., Heir, E., Fotland, T. Ø., ... \& Kruse, H. (2006). Triclosan and antimicrobial resistance in bacteria: an overview. Microbial drug resistance, 12(2), 83-90.

\section{Copyrights}

Copyright for this article is retained by the author(s), with first publication rights granted to the journal.

This is an open-access article distributed under the terms and conditions of the Creative Commons Attribution license (http://creativecommons.org/licenses/by/4.0/). 